\title{
Influence of the mode of application of universal adhesive systems on adhesive properties to fluorotic enamel
}

\author{
Andres Felipe Millan CARDENAS(a) \\ Ana ARMAS-VEJA(b) (iD \\ Juan Pablo RODRIGUEZ \\ VILLARREAL (b) \\ Fabiana Suelen Figueredo de \\ SIQUEIRA $^{(a)}$ \\ Luana Paraiso MUNIZ(a) \\ Veridiana Silva CAMPOS(c) \\ Alessandra REIS(c) \\ Alessandro Dourado LOGUERCIO ${ }^{(b, c)}$ \\ (a) Universidade CEUMA, Department of \\ Postgraduate Program in Dentistry, São Luis, \\ Maranhão, Brazil. \\ (b) Universidad Tecnológica Equinoccial - UTE, \\ Facultad de Ciencias de la Salud Eugenio \\ Espejo, Quito, Ecuador. \\ (c) Universidade Estadual de Ponta Grossa - \\ UEPG, Department of Restorative Dentistry, \\ Uvaranas, PR, Brazil.
}

Declaration of Interests: The authors certify that they have no commercial or associative interest that represents a conflict of interest in connection with the manuscript.

Corresponding Author:

Alessandro Dourado Loguercio

E-mail: aloguercio@hotmail.com

hitps://doi.org/10.1590/1807-3107bor-2019.vol33.0120

Submitted: December 19, 2018

Accepted for publication: August 20, 2019

Last revision: September 11, 2019
Abstract: The objective of this study is to compare the resin-enamel bond strength (muSBS), in-situ degree of conversion (DC), and the enamel-etching pattern (SEM/EDX) of universal adhesive systems when applied to sound and fluorotic enamel. Ninety-eight human molars were sectioned into 4 parts and divided into 24 groups according to 1) enamel surface (sound or fluorotic enamel), 2) adhesive system (Clearfil Universal Bond [CUB], Futurabond U [FBU], iBond Universal [IBU], and Scotchbond Universal [SBU]), and 3) application mode (etch-andrinse [ER], active self-etch [Active-SE], and passive self-etch [Passive$\mathrm{SE}]$ ). Specimens were stored at $37^{\circ} \mathrm{C}$, for 24 hours and tested at $1.0 \mathrm{~mm} /$ $\min (\mu \mathrm{SBS})$. Enamel-resin interfaces were evaluated for in-situ DC. The enamel-etching pattern was evaluated under a SEM/EDX. Data from muSBS and in-situ DC was analyzed using a three-way ANOVA and Tukey's test at $5 \%$ level of significance. For all adhesives, the ER resulted in a statistically significant higher mean muSBS than the passive-SE in both substrates $(p<0.001)$. For all adhesives, active-SE resulted in mean muSBS $(p>0.31)$ and in-situ DC $(p>0.45)$ that were statistically similar to those obtained with the ERs in both substrates. A statistically significant, higher mean muSBS and in-situ DC were obtained in sound enamel $(p<0.001)$ than in fluorotic enamel. In general, SBU showed higher mean values for muSBS and in-situ DC compared to those of CUB and IBU ( $p<0.001)$. ER and active-SE showed the deepest enamel-etching pattern in both substrates. A higher amount of fluor was observed in fluorotic enamel. The active application of universal adhesives in the SE-mode may be a viable alternative to increase the adhesive properties in sound and fluorotic enamel.

Keywords: Dental Enamel; Fluorosis, Dental; Dental Bonding; Shear Strength.

\section{Introduction}

Fluorine is an important element to control dental caries; however, an excess of this element during dentin formation may result in fluorosis. ${ }^{1,2}$ Dental fluorosis is a premature mineralization of external enamel, making the sub-surface enamel increasingly more porous and hypomineralized. ${ }^{3}$ These structural changes in enamel are characterized by opaque white areas or discolorations ranging from light yellow to dark brown, ${ }^{3}$ and 
this process could result in structure loss, leading to esthetic problems.

Different techniques have been proposed to improve the appearance of tooth stains caused by fluorosis. ${ }^{4,5}$ However, the choice among these treatments depends on the severity of the disease. ${ }^{6}$ In many cases, the restorative treatment is an alternative to conservative management of the discoloration produced by the lesion. ${ }^{6}$ However, the success of the restoration depends largely on the micromechanical interlocking of the adhesive system on the enamel. ${ }^{7}$

Several studies have found that bonding to fluorotic enamel is a clinical challenge $e^{8,9}$ because there are inherent structural differences between sound and fluorotic enamel, ${ }^{10,11}$ which suggests that dental fluorosis affects the bonding of composites to enamel, thereby compromising clinical success..$^{12,13}$

Clinical alternatives have been proposed to improve bonding to fluorotic enamel. One of them is ground fluorotic enamel, because the superficial removal of the enamel layer exposes a sub-superficial layer that is more reactive to bonding procedures. ${ }^{14,15}$ However, this alternative necessitates the removal of sound tissue, which is against the minimally invasive concept. Another option is to apply phosphoric acid, as in the etch-and-rinse (ER) strategy. ${ }^{16}$ However, this approach showed controversial results with fluorotic enamel, depending on the adhesive system used and severity of fluorotic enamel. ${ }^{17,18}$ Furthermore, the use of phosphoric acid requires several procedures (i.e., etching, washing, and drying) before adhesive application, increasing the number of steps for clinicians.

These recent advent of "universal" or "multi-mode" adhesive systems allows clinicians to circumvent these problems. These new adhesives are essentially one-step self-etch (SE) adhesives that may be used with phosphoric acid etching. ${ }^{19,20}$ This versatile bonding philosophy advocates the use of the simplest option from each strategy, ${ }^{19,20,21}$ with the advantage that the dentist can decide which adhesive strategy to use based on the specific clinical situation.

When different universal adhesives in the SE mode were evaluated in sound enamel, similar results were observed for active application of SE and enamel etching with phosphoric acid. ${ }^{22}$ This means that the application of enamel etching with phosphoric acid may not be crucial for their adhesion to enamel, and this in line with previous studies that evaluated bond strength to enamel with the oldest SE adhesives. ${ }^{23,24}$ However, as far as we know, there is no study that evaluated whether active application in the SE mode improves the bond strength of commercially available universal adhesives to fluorotic enamel.

Therefore, the aim of this study was to compare the resin-enamel microshear bond strength (muSBS), the in-situ degree of conversion (in-situ DC), and the enamel-etching pattern of four universal adhesive systems in sound and fluorotic enamel; when applied in the etch-and-rinse, active self-etch or passive selfetch mode, as well as, the semi-quantitative chemical microanalysis of sound and fluorotic enamel. The following null hypotheses were tested: the different application modes will not influence (1) $\mu S B S$, (2) the in-situ DC at the resin-fluorotic enamel interface, and (3) the enamel-etching pattern of universal adhesives.

\section{Methodology}

\section{Tooth selection and preparation}

We diagnosed dental fluorosis according to the severity of fluorosis using the Thylstrup and Fejerskov index (TFI). ${ }^{25}$ Prior to the selection of teeth, two examiners were trained on the calibration procedure described by Ermis et al. ${ }^{14}$ Ninety-eight caries-free, human molars were used. Forty- nine fluorosed teeth with a TFI score of 4 , and 49 teeth with TFI of 0 (without fluorosis; sound teeth) were obtained. We collected teeth after obtaining the patients' informed consent under a protocol approved by the Ethics Committee Review Board of the local university. The teeth were disinfected in $0.5 \%$ chloramine, stored in distilled water, and used within 6 months of extraction.

The roots of all teeth were removed by sectioning at the enamel-cementum junction. Each dental crown was then sectioned in the diagonals across the long axis of the tooth to produce four enamel specimens (buccal, lingual, and proximals). ${ }^{22} \mathrm{~A}$ total of 288 enamel specimens from 72 teeth, were used to evaluate muSBS and in-situ DC at the resin-enamel interfaces. Unground, 96 enamel specimens from 
24 teeth were used to evaluate the etching pattern produced on the fluorotic enamel surface. Additionally, 8 enamel specimens from 2 teeth were used for a semi-quantitative chemical microanalysis by EDX.

\section{Experimental design}

The enamel specimens were assigned to 24 experimental groups $(\mathrm{n}=16$ enamel specimens: 8 to $\mu$ SBS, 4 to in-situ DC, and 4 to enamel etching pattern per experimental group) according to the combination of 3 independent variables: 1) enamel surface (sound enamel or fluorotic enamel) ; 2) adhesive system [Clearfil Universal Bond (CUB; Kuraray Noritake Dental Inc, Tokyo, Japan), Futurabond U (FBU, VOCO, Cuxhaven, Germany), iBond Universal (IBU, Heraeus Kulzer, Hanau, Germany), Scotchbond Universal (SBU, also known as Single Bond Universal in some countries, 3M Oral Care, St. Paul, USA)]; and 3) application mode [etch-and-rinse (ER mode), active self-etch (Active-SE), and passive self-etch (Passive-SE)]. The adhesive system was applied according to the manufacturer's instructions, as described in Table 1. Enamel specimens were randomized using computergenerated numbers for all tests performed on sound and fluorotic enamel substrates.

\section{Sample size calculation}

For the enamel bond strength values, the mean of microshear bond strength values obtained in ER mode for universal adhesives, when applied in enamel was considered for sample size calculation. ${ }^{22}$ In previous literature, the mean and standard deviation of several universal adhesives evaluated was $20.4 \pm 3.0$. Using an $\alpha$ of 0.05 , a power of $80 \%$ and a two-sided test, the minimal sample size was 8 enamel specimens in each group in order to detect a difference of $5 \mathrm{MPa}$ among the tested groups.

A second sample size was also calculated by degree of conversion. The mean of degree of conversion values of universal adhesives obtained in ER mode when applied in enamel was considered to sample size calculation. ${ }^{22}$ In previous literature, mean and standard deviation of several universal adhesives evaluated was $68.8 \pm 4.0$. Using an $\alpha$ of 0.05 , a power of $80 \%$ and a two-sided test, the minimal sample size was 4 enamel specimens in each group in order to detect a difference of $9 \%$ in degree of conversion among the tested.

\section{Microshear bond strength test ( $\mu$ SBS)}

Each enamel specimen ( $\mathrm{n}=8$ for group) was embedded in a polyvinyl chloride tube $(10 \mathrm{~mm}$ high $\times 13 \mathrm{~mm}$ diameter) using a chemically cured acrylic resin (Jet Clássico, São Paulo, SP, Brazil) so that the enamel surface was left exposed at the top of the cylinder. The bonding area was isolated according to the protocol suggested by Shimaoka's study. ${ }^{26}$ Six to eight perforations, with an internal diameter of $0.8 \mathrm{~mm}$, were made in an acid-resistant, double-faced adhesive tape (Adelbras Ind e Com Adesivos Ltda, São Paulo, SP, Brazil) that was adapted to the enamel surface. This procedure was performed using the Hygienic Ainsworth-style rubber-dam punch (Coltene, Alstatten, Switzerland). The variation in the number of perforations for each enamel surface was dependent on the dimensions of the enamel specimens.

The universal adhesives were applied to the enamel surface as described in Table 1. A single operator performed all bonding procedures according to the following description:

a. ER mode: The phosphoric acid gel of each adhesive system was applied and left undisturbed for the time recommended by each manufacturer. Then, the surfaces were water rinsed with an air-water syringe for 10 seconds;

b. Passive-SE: Each adhesive was spread over the enamel surface and left undisturbed for 20 seconds;

c. Active-SE: Each adhesive was actively applied on the enamel surface for 20 seconds. The manual pressure exerted on the microbrush (Microbrush International, Grafton, USA) during application was equivalent to $35 \mathrm{~g}$.

After application of the adhesive system, polyethylene transparent Tygon tubes (Tygon Medical Tubing Formulations 54-HL, Saint Gobain Performance Plastics, Akron, USA), with the same internal diameter as the perforations and a height of $0.5 \mathrm{~mm}$, were positioned on the perforations over the double-faced tape, ensuring that their lumens coincided with the circular areas exposed by the perforations. A resin composite (Opallis, FGM, 
Table 1. Adhesive system (Batch Number), Composition, and Application Mode of the adhesive systems according to the manufacturer's instructions.

\begin{tabular}{llll}
\hline $\begin{array}{l}\text { Adhesive (Batch } \\
\text { number) }\end{array}$ & Composition* & \multicolumn{2}{c}{ Application mode } \\
\cline { 3 - 4 }
\end{tabular}

1. Etchant: $35 \%$ phosphoric acid, colloidal silica, polyethyleneglycol, pigment, and water (K-ETCHANT)

2. Adhesive: HEMA, MDP, Bis-GMA, ethanol, camphorquinone, hydrophilic aliphaticdimethacrylate, silane

Clearfil Universal Bond (CUB)-700018 coupling agent, colloidal silica, water, and accelerators
1. Apply bond and rub (ACTIVEa) or left undisturbed (PASSIVE) for $20 \mathrm{~s}$

1. Apply etchant for $10 \mathrm{~s}$
2. Rinse thoroughly
3. Light cure for $10 \mathrm{~s}$ at $1200 \mathrm{~mW} / \mathrm{cm} 2$
3. Dry

4. Apply adhesive as for the self-etch mode

1. Etchant: $34 \%$ phosphoric acid water, synthetic amorphous silica,

Futurabond $U(\mathrm{FBU}) \quad$ 2. Adhesive: Liquid 1: Acidic adhesive, $-1705288$ polyethylene glycol, water, synthetic amorphous silica, polyethylene glycol, aluminum oxide (Vococid Etch 35\%

Gel) monomer HEMA BISGMA, HEDMA, UDMA Catalyst. Liquid 2: Ethanol initiator, catalyst
1. Apply the adhesive to the entire preparation with a microbrush and rub it (ACTIVE) or leave undisturbed (PASSIVE ${ }^{a}$ )

for $20 \mathrm{~s}$. If necessary, rewet the disposable applicator during treatment

2. Direct a gentle stream of air over the liquid for about $5 \mathrm{~s}$ until it no longer moves, and the solvent is evaporated completely

3. Light cure for $10 \mathrm{~s}$ at $1,200 \mathrm{~mW} / \mathrm{cm}^{2}$
1. Apply etchant for $15 \mathrm{~s}$

2. Rinse for $10 \mathrm{~s}$

3. Air dry $2 \mathrm{~s}$

4. Apply adhesive as for the self-etch mode liquid for about $5 \mathrm{~s}$ until it no longer
1. Etchant: $35 \%$ phosphoric acid, colloidal silica, polyethyleneglycol, pigment, and water (K-ETCHANT) polyethyleneglycol, pigment, and water (iBOND Etch 35 Gel).

2. Adhesive: Acetone, UDMA, TEGDMA,

4-methacryloxyethyltrimellitic anhydride, photoinitiator.

1. Apply the adhesive to the entire preparation with a microbrush and rub it (ACTIVE') or leave undisturbed (PASSIVE)

for $20 \mathrm{~s}$. If necessary, rewet the disposable applicator during treatment

2. Direct a gentle stream of air over the moves, and the solvent is evaporated completely

3. Light cure for $10 \mathrm{~s}$ at $1,200 \mathrm{~mW} / \mathrm{cm} 2$

1. Apply the adhesive to the entire

1. Etchant: $34 \%$ phosphoric acid, water, synthetic amorphous silica, polyethylene glycol,aluminum oxide (Scotchbond Universal Etchant)

2. Adhesive: MDP phosphate monomer, dimethacrylate resins, Bis-

Scotchbond Universal (SBU) -638367 GMA, HEMA, methacrylatemodified polyalkenoic acid copolymer,camphor quinone, filler, ethanol, water, initiators, silane preparation with a microbrush and rub it in (ACTIVE ${ }^{a}$ ) or left undisturbed (PASSIVE)

for $20 \mathrm{~s}$. If necessary, rewet the disposable applicator during treatment

2. Direct a gentle stream of air over the liquid for about $5 \mathrm{~s}$ until it no longer moves, and the solvent is evaporated completely

3. Light cure for $10 \mathrm{~s}$ at $1,200 \mathrm{~mW} / \mathrm{cm} 2$
1. Apply etchant for $15 \mathrm{~s}$

2. Rinse for $10 \mathrm{~s}$

3. Dry

4. Apply adhesive as for the self-etch mode.

1. Apply etchant for $15 \mathrm{~s}$

2. Rinse for $10 \mathrm{~s}$

3. Air dry $2 \mathrm{~s}$

4. Apply adhesive as for the self-etch mode

HEMA, 2-hydroxyethyl methacrylate; MDP, methacryloyloxydecyldihydrogen phosphate; Bis-GMA, bisphenolglycidyl methacrylate; UDMA, urethanedimethacrylate; HEDMA, hexamethylenedimethacrylate. ${ }^{a}$ As per manufacturer's instructions 
Joinville, Brazil) was carefully packed inside each tube, and a clear Mylar matrix strip was placed over the filled Tygon tube and pressed gently into place. The resin composite was light cured for 20 seconds using an LED light-curing unit set at $1200 \mathrm{~mW} / \mathrm{cm}^{2}$ (Radii- cal, SDI Limited, Bayswater, Victoria, Australia). A radiometer (Demetron L.E.D. Radiometer, Kerr Sybron Dental Specialties, Middleton, USA) was used to check the light intensity for every five specimens. These procedures were carried out under 10× magnifying loupes.

After storage of the specimens in distilled water for 24 hours at $37^{\circ} \mathrm{C}$, the Tygon tubes and the double-faced adhesive tape were carefully removed, using a blade, to expose the composite cylinders. Each specimen was examined under a stereomicroscope at 10× magnification. The bonded cylinder was discarded if there was evidence of porosities or gaps at the interface. ${ }^{27}$

The specimens were attached to a shear-testing fixture (Odeme Biotechnology, Joaçaba, SC, Brazil) and tested in a universal testing machine (Kratos IKCL 3-USB, Kratos Equipamentos Industriais Ltda, Cotia, Brazil). Each specimen was positioned in the universal testing machine, and a thin wire $(0.2 \mathrm{~mm}$ diameter $)$ was looped around the base of each composite cylinder. The wire contacted the composite resin cylinder along half of its circumference. The setup was maintained in alignment (resin-enamel interface, the wire loop, and the center of the load cell) to ensure the correct orientation of the shear forces. The crosshead speed was set at $1 \mathrm{~mm} / \mathrm{min}$ until failure.

The $\mu$ SBS values ( $\mathrm{MPa}$ ) were calculated by dividing the load at failure by the surface area $\left(\mathrm{mm}^{2}\right)$. After testing, the specimens were examined through an optical microscope (SZH-131, Olympus Ltd, Tokyo, Japan) at 100× magnification to define the location of the bond failure. The type of failure was determined based on the percentage of substratefree material as follows: adhesive/mixed ([A/M] failure at the resin/enamel interface, or failure at the resin/enamel interface with partial cohesive failure of the neighboring substrates), cohesive ([CE] failure exclusive within enamel or [CR] failure exclusive within resin composite), and premature failures (PF).

\section{In-situ DC}

Enamel specimens ( $n=4$ for group) were prepared according to previous studies. ${ }^{22,28}$ Four enamel specimens were assigned for each group as described earlier for the $\mu \mathrm{SBS}$ test. The adhesives were applied, and composite resin buildups were constructed on the bonded enamel using the same materials and protocols described for the $\mu$ SBS test. After storage of the restored teeth in distilled water at $37^{\circ} \mathrm{C}$ for 24 hours, the resin-enamel specimens were longitudinally sectioned across the bonded interface with a low-speed diamond saw (Isomet, Buehler Ltd, Lake Bluff, USA) to obtain two resinenamel slices.

The resin-enamel slices were wet polished with 1500-, 2000-, and 2500-grit silicon carbide paper (SiC) paper for 15 seconds each. Then, they were ultrasonically cleaned for 20 minutes in distilled water and stored in water for 24 hours at $37^{\circ} \mathrm{C}$. The micro-Raman equipment (XploRA ONE ${ }^{\mathrm{TM}}$ Raman microscope, HORIBA Scientific, New Jersey, USA), was first calibrated for zero and then for coefficient values using a silicon sample. The samples were analyzed using a 638-nm diode laser through an X100/0.9 NA air objective. The Raman signal was acquired using a 600-lines/mm grafting centered between 400 and $1800 \mathrm{~cm}^{-1}$, and the employed parameters were $100 \mathrm{~mW}$, spatial resolution of $3 \mu \mathrm{m}$, spectral resolution of $5 \mathrm{~cm}^{-1}$, accumulation time of 25 seconds, with five co-additions.

Spectra were taken at the resin-enamel adhesive interface at 3 dissolver sites for each specimen. Spectra of uncured adhesives were taken as references. The ratio of double-bond content of monomer to polymer in the adhesive was calculated according to the following formula: DC $(\%)=(1-[R$ cured $/ R$ uncured] $) \times 100$, where $R$ is the ratio of aliphatic and aromatic peak intensities at $1639 \mathrm{~cm}^{-1}$ and $1609 \mathrm{~cm}^{-1}$ in cured and uncured adhesives.

\section{Enamel etching pattern}

The enamel-etching pattern ( $n=4$ for group) was evaluated on the enamel surface under a scanning electron microscope (SEM; VEGA 3 TESCAN, Shimadzu, Tokyo, Japan). For this purpose, the adhesives were applied in the SE mode under different 
experimental conditions (Table 1), but the adhesives were not light cured. For the ER mode, the phosphoric acid gel was applied on enamel for 30 seconds, rinsed for 10 seconds, and air-dried according to each manufacturer's instructions.

The enamel surfaces were immediately stored in acetone for 24 hours to dissolve the resinous material on the enamel surface. ${ }^{29}$ Then, the specimens were rinsed off in deionized water ( $5 \mathrm{~min}$ ), a $96 \%$ alcohol bath (5 $\mathrm{min})$, and deionized water (5 $\mathrm{min}$ ) to dissolve and remove the SE primer and the adhesive resins. ${ }^{29}$

All specimens were dried and dehydrated in a desiccator for 12 hours, and the conditioned enamel surfaces were sputter coated with gold/palladium in a vacuum evaporator (SCD 050, Balzers, Schaan, Liechtenstein). The entire surface of treated enamel was examined under a SEM (VEGA 3 TESCAN, Shimadzu, Tokyo, Japan). Photomicrographs of representative surface areas were taken at $5000 \times$ magnification.

\section{Energy dispersive X-ray spectroscopy analysis (EDX)}

For a semi-quantitative chemical microanalysis using EDX, the fluorotic and sound enamel specimens $(n=4$ for enamel surface) were evaluated under a scanning electron microscope (MIRA, Tescan Orsay Holding, Warrendale, USA). After sectioning as previously described, the enamel specimens were flattened with \#600-grit SiC for 60 seconds each, rinsed off in deionized water ( 5 minutes) and, dried and dehydrated in a desiccator for 12 hours. Then, all specimens were sputter coated with gold/palladium in a vacuum evaporator (SCD 050, Balzers, Schaan, Liechtenstein) and the entire surface of enamel was examined. The semi-quantitative chemical microanalysis was performed by the quantification of the elements in percentage $(\mathrm{Ca}, \mathrm{F}$ and $\mathrm{P})$ using EDX. The analysis was performed along the entire length of the flattened surface.

\section{Statistical analysis}

The muSBS of all specimens with adhesive/mixed failure mode from the same enamel specimens were averaged for statistical purposes. Similarly, the same procedure was performed for the in-situ DC measurements, so that the experimental unit in this study was the enamel specimens. Specimens with cohesive and premature failures were not included in the data analysis. Data from $m \mu S B S$ and in-situ DC were analyzed separately using three-way analysis of variance (ANOVA) (enamel surface vs. application mode vs. adhesive systems) and the Tukey's posthoc test at $\mathrm{a}=0.05$. The enamel etching pattern and semi-quantitative chemical microanalysis by EDX was only evaluated qualitatively.

\section{Results}

\section{Microshear bond strength}

Most of the specimens (98.1\%-100 \%) showed adhesive/mixed failures (Table 2). The microshear bond strength data is shown in the Table 3 . The cross-product interaction was statistically significant ( $p<0.001$; Table 3). For all universal adhesives, the ER mode resulted in a statistically significant, higher mean muSBS when compared with the passive-SE groups in sound and fluorotic enamel ( $p=0.001$; Table 3). Regarding to active-SE mode, for all universal adhesives, the mean bond strengths were statistically similar to those obtained with the respective ER application mode in sound and fluorotic enamel ( $p>0.31$; Table 3 ). The only exception was when CUB was applied in sound enamel in the active-SE mode, it resulted in mean bond strengths that were statistically higher compared with those obtained with the respective ER application mode $(p=0.001$; Table 3).

When sound and fluorotic enamel are compared, for all universal adhesives, statistically significant higher mean $m \mu S B S$ were obtained in sound enamel $(p=0.001$; Table 3). Also, in sound and fluorotic enamel, the mean of $\mathrm{m} \mu \mathrm{SBS}$ was significant higher to SBU when compared to FBU and IBU ( $p$ > 0.31; Table 3). However, SBU and CUB showed similar and higher mean of muSBS when applied in the sound and fluorotic enamel (ER mode and Active-SE) $(p=0.46$; Table 3). Lower $\mathrm{m} \mu \mathrm{SBS}$ was usually observed for FBU and IBU in all experimental conditions ( $p=0.001$; Table 3$)$. 
Table 2. Number of specimens (\%) according to fracture mode for all experimental groups*.

\begin{tabular}{|c|c|c|c|c|c|c|c|c|c|}
\hline \multirow{2}{*}{ Adhesives } & \multirow{2}{*}{$\begin{array}{l}\text { Application } \\
\text { mode }\end{array}$} & \multicolumn{4}{|c|}{ Sound enamel } & \multicolumn{4}{|c|}{ Fluorotic enamel } \\
\hline & & $\mathrm{A} / \mathrm{M}$ & CE & CR & PF & $\mathrm{A} / \mathrm{M}$ & CE & $\mathrm{CR}$ & PF \\
\hline \multirow[t]{3}{*}{ CUB } & ER mode & $49(98)$ & $1(2)$ & $0(0)$ & $0(0)$ & $56(96)$ & $0(0)$ & $1(2)$ & $1(2)$ \\
\hline & Passive-SE** & $55(100)$ & $0(0)$ & $0(0)$ & $0(0)$ & $54(98)$ & $1(2)$ & $0(0)$ & $0(0)$ \\
\hline & Active-SE & $50(98)$ & $0(0)$ & $1(2)$ & $0(0)$ & $58(100)$ & $0(0)$ & $0(0)$ & $0(0)$ \\
\hline \multirow[t]{3}{*}{ FBU } & ER mode & 61 (98) & $0(0)$ & $1(2)$ & $0(0)$ & $50(96)$ & $0(0)$ & $0(0)$ & $2(4)$ \\
\hline & Passive-SE & 47 (96) & $0(0)$ & $0(0)$ & $2(4)$ & $48(100)$ & $0(0)$ & $0(0)$ & $0(0)$ \\
\hline & Active-SE & $56(100)$ & $0(0)$ & $0(0)$ & $0(0)$ & $60(96)$ & $0(0)$ & $0(0)$ & $2(4)$ \\
\hline \multirow[t]{3}{*}{$\mathrm{IBU}$} & ER mode & $52(98)$ & $0(0)$ & $0(0)$ & $1(2)$ & $48(96)$ & $1(2)$ & $0(0)$ & $1(2)$ \\
\hline & Passive-SE & 57 (98) & $0(0)$ & $0(0)$ & $1(2)$ & $54(96)$ & $0(0)$ & $0(0)$ & $2(4)$ \\
\hline & Active-SE & $60(96)$ & $0(0)$ & $1(2)$ & $1(2)$ & $58(96)$ & $0(0)$ & $0(0)$ & $2(4)$ \\
\hline \multirow[t]{3}{*}{ SBU } & ER mode & $60(100)$ & $0(0)$ & $0(0)$ & $0(0)$ & $54(100)$ & $0(0)$ & $0(0)$ & $0(0)$ \\
\hline & Passive-SE & $54(100)$ & $0(0)$ & $0(0)$ & $0(0)$ & $50(100)$ & $0(0)$ & $0(0)$ & $0(0)$ \\
\hline & Active-SE & $61(96)$ & $0(0)$ & $1(2)$ & $1(2)$ & $58(98)$ & $1(2)$ & $0(0)$ & $0(0)$ \\
\hline
\end{tabular}

${ }^{*} \mathrm{~A} / \mathrm{M}$ : adhesive/mixed fracture mode; CE: cohesive-enamel fracture mode; CR: cohesive-resin fracture mode; PF: premature failure. ${ }^{* *} \mathrm{SE}:$ self-etch.

Table 3. Microshear bond strength (mSBS in MPa) values (means \pm standard deviations) of the different experimental groups*.

\begin{tabular}{lccccccc}
\hline \multirow{2}{*}{ Adhesives } & \multicolumn{3}{c}{ Sound enamel } & & \multicolumn{3}{c}{ Fluorotic enamel } \\
\cline { 2 - 7 } & ER mode** & Passive-SE*** & Active-SE & ER mode & Passive-SE & Active-SE \\
\hline CUB & $18.32 \pm 1.2 \mathrm{~B}, \mathrm{a}$ & $14.51 \pm 1.9 \mathrm{D}, \mathrm{b}$ & $20.03 \pm 1.2 \mathrm{~A}, \mathrm{a}$ & $16.45 \pm 1.9 \mathrm{C}, \mathrm{a}$ & $10.39 \pm 1.9 \mathrm{E}, \mathrm{b}$ & $13.10 \pm 1.7 \mathrm{C}, \mathrm{D} \mathrm{a}, \mathrm{b}$ \\
FBU & $16.34 \pm 1.8 \mathrm{~A}, \mathrm{~b}$ & $13.78 \pm 2.1 \mathrm{~B}, \mathrm{~b}$ & $16.04 \pm 1.7 \mathrm{~A}, \mathrm{~b}$ & $13.63 \pm 2.2 \mathrm{~B}, \mathrm{~b}$ & $9.10 \pm 1.2 \mathrm{C}, \mathrm{b}$ & $12.66 \pm 1.3 \mathrm{~B}, \mathrm{Cb}$ \\
$\mathrm{IBU}$ & $16.20 \pm 1.6 \mathrm{~A}, \mathrm{~b}$ & $12.47 \pm 1.9 \mathrm{~B}, \mathrm{~b}$ & $15.22 \pm 1.4 \mathrm{~A}, \mathrm{~b}$ & $12.35 \pm 1.7 \mathrm{~B}, \mathrm{~b}$ & $8.97 \pm 1.0 \mathrm{C}, \mathrm{b}$ & $11.45 \pm 1.2 \mathrm{~B}, \mathrm{~b}$ \\
SBU & $18.78 \pm 2.3 \mathrm{~A}, \mathrm{a}$ & $17.56 \pm 1.6 \mathrm{~A}, \mathrm{a}$ & $17.31 \pm 1.2 \mathrm{~A}, \mathrm{a}$ & $15.32 \pm 2.1 \mathrm{~B}, \mathrm{a}$ & $12.12 \pm 2.2 \mathrm{C}, \mathrm{a}$ & $14.75 \pm 1.4 \mathrm{~B}, \mathrm{a}$ \\
\hline
\end{tabular}

*Capital letters mean statistically significant difference within row; lower case letters mean statistically significant differences within columns (Three-way ANOVA; Tukey test, $p<0.05)$. ${ }^{* *}$ ER: etch-and-rinse, ${ }^{* *}$ SE: self-etch.

\section{In-situ DC}

The in-situ degree of conversion values is shown in the Table 4 . The cross-product interaction was statistically significant ( $p=0.0001$; Table 4$)$. For all adhesives, the ER mode resulted in statistically significant higher mean of in-situ DC when compared with the passive-SE groups in sound and fluorotic enamel ( $p=0.0001$; Table 4). Regarding to active-SE mode, for all universal adhesives, the mean in-situ DC was statistically similar to those obtained with the respective ER application mode in sound and fluorotic enamel ( $p>0.45$; Table 4$)$. The only exception was CUB in the sound enamel, which, when applied in the active-SE mode, resulted in a mean in-situ DC that was statistically higher compared with those obtained with the respective ER application mode $(p=0.0001 ;$ Table 4).
When comparing sound and fluorotic enamel in all adhesive strategies, statistically significant higher mean in-situ DC were obtained in sound enamel $(\mathrm{p}<0.0001$; Table 4). For both sound and fluorotic enamel, the in-situ DC was significantly higher for SBU compared to all universal adhesives tested ( $p>$ 0.52; Table 4). The only exception was CUB for sound enamel, which, when applied in the active-SE mode, resulted in a mean in-situ DC that was statistically similar compared with SBU ( $p=0.32$; Table 4$)$. Lower in-situ DC was generally observed for FBU and IBU (ER mode in both substrates) and IBU (passive-SE in fluorotic enamel) $(p<0.0001$; Table 4).

\section{Enamel-etching pattern}

SEM images of enamel surfaces under different experimental conditions are depicted in Figure 1. 
Independent of the enamel surface, ER completely removed the smear layer from both sound and fluorotic enamel, promoting the deepest and most pronounced etching pattern when compared with passive-SE (Figure 1). When a universal adhesive was applied in the passive-SE mode on sound and

Table 4. In-situ DC (\%) values (means \pm standard deviations) of the different experimental groups().

\begin{tabular}{lcccccc}
\hline \multirow{2}{*}{ Adhesives } & \multicolumn{3}{c}{ Sound enamel } & & \multicolumn{2}{c}{ Fluorotic enamel } \\
\cline { 2 - 8 } & ER mode* & Passive-SE* & Active-SE & ER mode & Passive-SE & Active-SE \\
\hline CUB & $65.07 \pm 3.3 \mathrm{~B}, \mathrm{~b}$ & $54.18 \pm 2.3 \mathrm{C}, \mathrm{b}$ & $70.20 \pm 2.2 \mathrm{~A}, \mathrm{a}$ & $56.17 \pm 2.2 \mathrm{C}, \mathrm{b}$ & $49.37 \pm 1.6 \mathrm{D}, \mathrm{b}$ & $55.11 \pm 1.5 \mathrm{C}, \mathrm{b}$ \\
$\mathrm{FBU}$ & $60.65 \pm 2.4 \mathrm{~A}, \mathrm{c}$ & $52.06 \pm 1.9 \mathrm{~B}, \mathrm{~b}$ & $59.30 \pm 2.8 \mathrm{~A}, \mathrm{~b}$ & $51.20 \pm 1.5 \mathrm{~B}, \mathrm{c}$ & $48.24 \pm 2.0 \mathrm{C}, \mathrm{B}$ & $53.45 \pm 2.9 \mathrm{~B}, \mathrm{~b}$ \\
$\mathrm{IBU}$ & $58.79 \pm 2.8 \mathrm{~A}, \mathrm{c}$ & $53.98 \pm 1.8 \mathrm{~B}, \mathrm{~b}$ & $58.48 \pm 1.7 \mathrm{~A}, \mathrm{~b}$ & $50.86 \pm 3.5 \mathrm{~B}, \mathrm{c}$ & $45.28 \pm 0.5 \mathrm{C}, \mathrm{c}$ & $52.35 \pm 2.8 \mathrm{~B}, \mathrm{~b}$ \\
$\mathrm{SBU}$ & $71.39 \pm 1.4 \mathrm{~A}, \mathrm{a}$ & $66.43 \pm 2.5 \mathrm{~B}, \mathrm{a}$ & $72.13 \pm 1.3 \mathrm{~A}, \mathrm{a}$ & $60.17 \pm 2.1 \mathrm{C}, \mathrm{a}$ & $51.67 \pm 1.6 \mathrm{D}, \mathrm{a}$ & $61.16 \pm 2.6 \mathrm{C}, \mathrm{a}$ \\
\hline
\end{tabular}

*Capital letters mean statistically significant difference within row; lower case letters mean statistically significant differences within columns

(Three-way ANOVA; Tukey test, $\mathrm{p}<0.05)$; ${ }^{* *}$ ER: etch-and-rinse, ${ }^{* * * S E}$ : self-etch.

\section{SOUND ENAMEL}
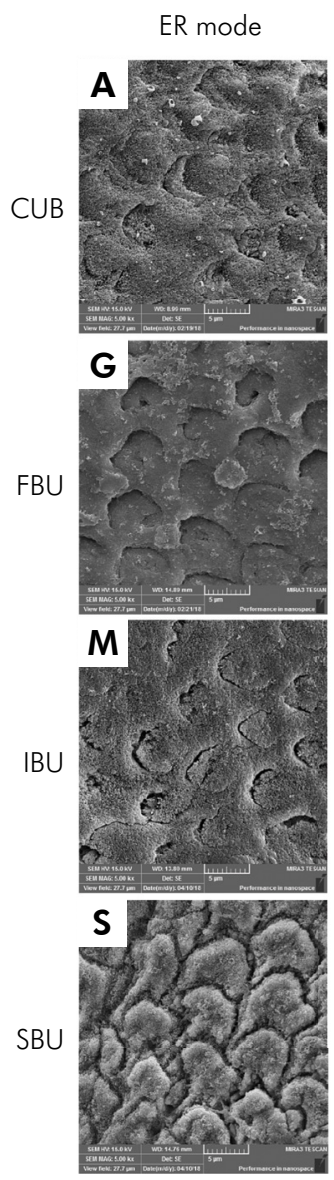
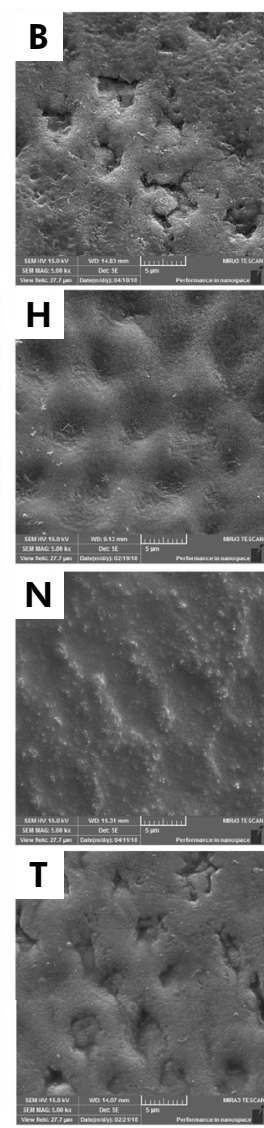

Passive-SE
Active-SE
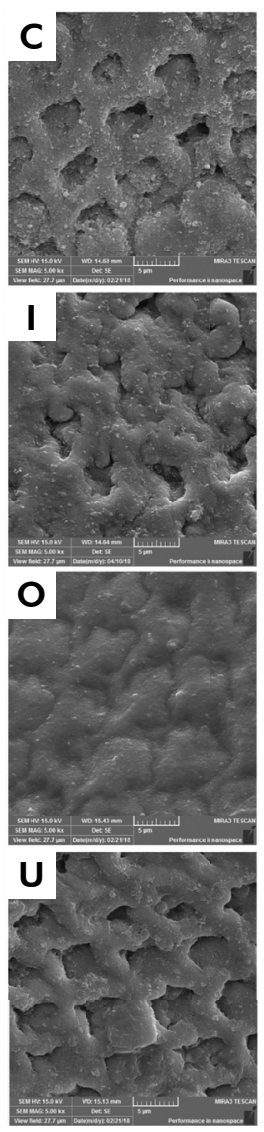

ER mode
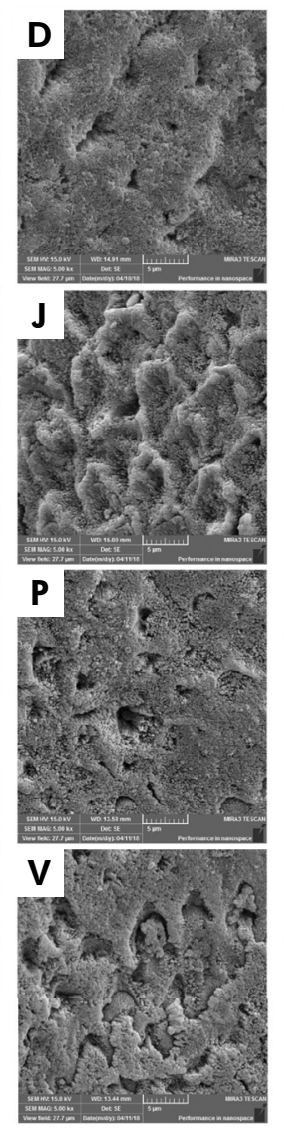

FLUOROTIC ENAMEL

Passive-SE
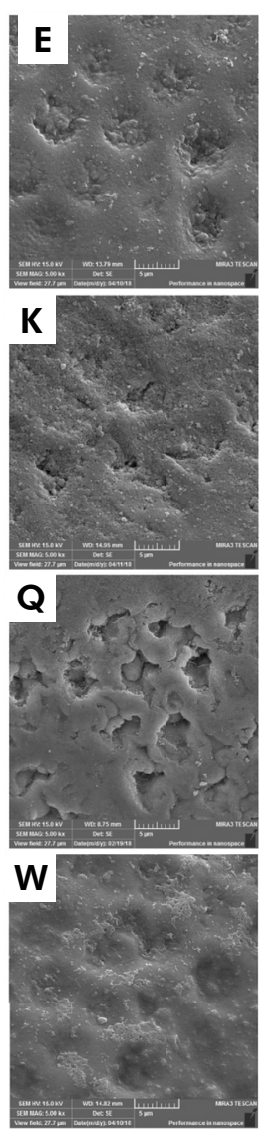

Active-SE
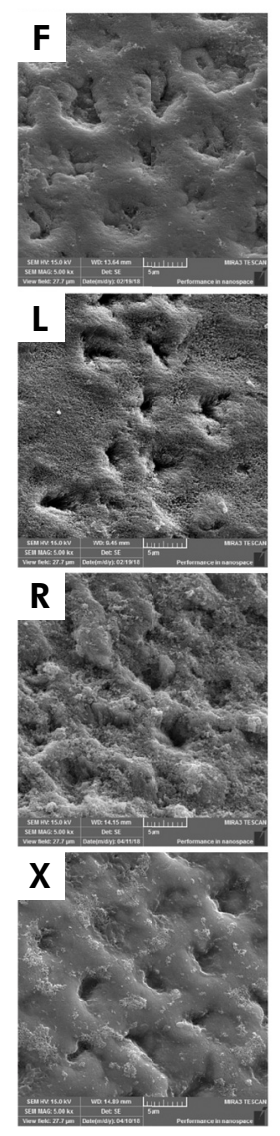

Figure 1. Representative morphology of sound and fluorotic enamel treated with four universal adhesives in different application mode. A greater dissolution of the prisms was observed for ER application mode for sound enamel (A, G, M, S) and fluorotic enamel $(D, J, P, V)$. Conversely, a lower enamel dissolution was observed for passive-SE in both substrates (sound [B, $H, N, T]$ and fluorotic $[E, H, Q, W])$. The active-SE application resulted in a more pronounced etching pattern with exposure of the subsurface enamel for sound enamel $(C, I, O, U)$ and fluorotic enamel $(F, L, R, X)$, mainly when compared with passive-SE. 
fluorotic enamel, signs of mild etching, with a few islands of enamel conditioning, and shallow fossae were observed in some areas.

In both substrates, the active-SE application improved the etching pattern. and promoted the increase of the exposure of the enamel prisms also increased with more signs of hydroxyapatite dissolution for all universal adhesives evaluated (Figure 1). In addition, more irregular fossae and grooves that were deeper than those found in passive-SE were found in active-SE. The active-SE in fluorotic enamel showed more exposure of the periphery of prisms with more signs of fluorapatite dissolution than that of passive-SE (Figure 1). When sound and fluorotic enamel are compared, overall, there is an increase in micro-irregularity and porosity along the entire enamel fluorotic surface.

\section{Energy dispersive X-ray spectroscopy analysis (EDX)}

The representative semi-quantitative chemical microanalysis of the fluorotic and sound enamel are shown in Figure 2. Fluorotic enamel presented the lowest $\mathrm{Ca}$ and $\mathrm{P}$ content on the surface compared to the sound enamel. However, an increase in the fluoride peak intensity was observed on the fluorotic enamel surface.

\section{Discussion}

The results showed that the adhesive applied in ER mode resulted in higher bond strength than in passive-SE application in sound and fluorotic enamel, which led us to partially reject the first null hypothesis. Although universal adhesive systems have been designed to simplify the concept of adhesive strategies, they are essentially one-step SE adhesive systems with limited ability to etch enamel. ${ }^{30}$ This means that even for universal adhesives, bonding to enamel is still a concern for clinicians when they are used in passive-SE mode.

Furthermore, the results showed that when a universal adhesive is applied in the passive-SE mode, there was a significant decrease in in-situ DC inside the hybrid layer formed in sound and fluorotic enamel when compared with other groups, which led us to partially reject the second null hypothesis. This could be explained by a higher amount of solvent inside the adhesive layer after the light-curing procedure, when adhesive is applied passively. The presence of solvent after the light-curing procedure increases the number of voids and porosity; and consequently decreases the mechanical properties of the adhesive layer. ${ }^{31}$ This could be the reason for the jeopardized bond strength values observed in our study.

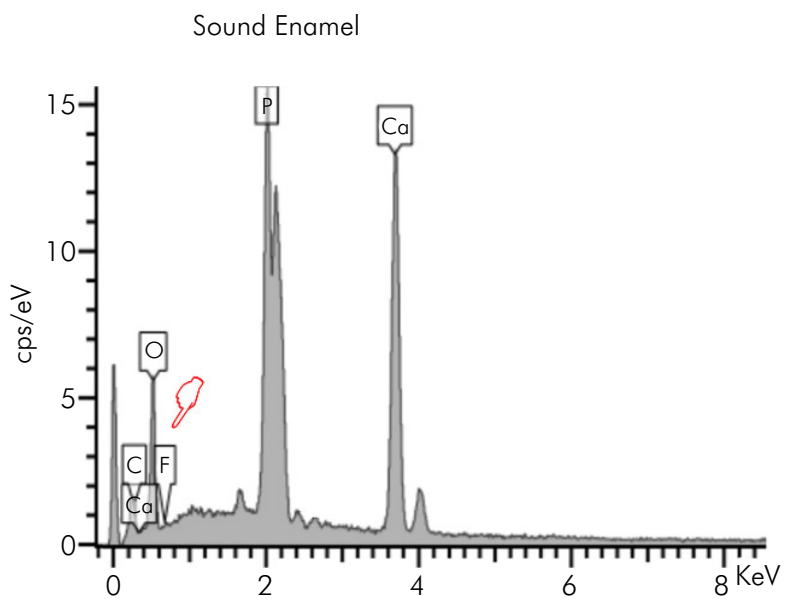

Fluorotic Enamel

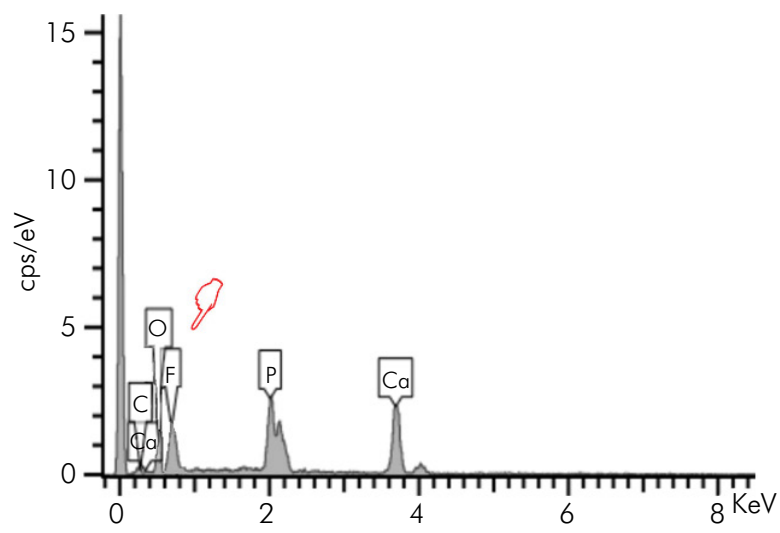

Figure 2. Representative energy dispersive X-ray spectroscopy of sound and fluorotic enamel. After flattening, the surface fluorotic enamel showed a decreased $\mathrm{Ca}$ and $\mathrm{P}$ elements. Fluoride content was higher on fluorotic enamel compared to sound enamel (red hands). 
SEM image analysis showed a very superficial enamel morphology alteration created by the passive-SE mode. A retentive pattern was observed created by phosphoric acid for sound and fluorotic enamel (Figure 1). This corresponds with previous findings for several commercially available universal adhesives $^{22,28}$ leading us to reject the third null hypothesis. Actually, universal adhesives are considered ultra-mild acidic SEs. ${ }^{21,32}$ Therefore, with only a shallow inter-crystallite infiltration of the monomers and lack of inter-prismatic resin tag formation, this finding was expected. This means that when SE adhesives are applied passively, they only interact superficially with enamel resulting in a reduced potential for micromechanical interlocking, ${ }^{22}$ and a lower $\mathrm{m} \mu \mathrm{SBS}$ to enamel.

When universal adhesives were applied actively, a significant increase in the mean bond strengths and in-situ DC were observed for sound and fluorotic enamel. The active application mode improves enamel demineralization and interaction of resin monomers with prismatic and interprismatic areas, independent of the universal adhesive used. This is achieved by the carrying of fresh resin monomers to the deeper enamel layers during active application. This finding was previously observed for the original SEs ${ }^{24}$ and universal adhesives applied in the SE mode. ${ }^{22}$

The etching pattern achieved with the active-SE mode was not as pronounced as that produced in the ER mode. Nevertheless, our SEM images support the findings that a deeper demineralization occurred when all universal adhesives were applied in the active-SE mode in sound and fluorotic enamel when compared with the passive-SE mode (Figure 1).

In addition, the active application of universal adhesive in the SE mode may increase outward solvent diffusion, mainly for adhesives composed of solvent with low vapor pressures, such as water. ${ }^{33}$ This solvent evaporation may allow room for changes in polymer topology by reducing the intrinsic fraction of nanopores, allowing increased cross-linking and improved mechanical properties of the polymer inside the enamel hybrid layer. ${ }^{34}$ This explains why the highest in-situ DC was obtained when adhesives were applied in the active-SE mode.
Conversely, CUB showed a higher mean m $\mu$ SBS and in-situ DC in sound enamel when applied actively compared with the ER mode. Previously it has been demonstrated that CUB and FBU are more acidic $(\mathrm{pH}$ 2.3) compared with SBU ( $\mathrm{pH} 2.7) .22,28$ This lower $\mathrm{pH}$ potentiates the demineralization mechanism and improves the superficial interaction of the adhesive system..$^{35}$ In addition, the uneven topography of enamel surfaces etched with phosphoric acid may increase the entrapment of solvents and air into the deeper prismatic and interprismatic portions of the etched enamel, leading to a lower in-situ DC. ${ }^{28}$

Unfortunately, although FBU showed similar $\mathrm{pH}$ to CUB, the former did not show the same performance in terms of bond strength and in-situ DC when active-SE was compared to ER. This could be due to the different compositions of the universal adhesives used in this study.

Although the exact composition of each universal adhesive is proprietary information, CUB is a 10-MDPbased adhesive, and as per the MSDS of FBU, it does not have 10-MDP. This acidic monomer is responsible for the chemical interaction with hydroxyapatite and forms a hydrolytically stable nanolayer with calcium, ${ }^{36}$ increasing the mechanical strength ${ }^{37}$ and protecting against hydrolysis. ${ }^{38}$ However, future studies need to be done to evaluate the effect of active-SE application on MDP-containing and MDP-free adhesive.

IBU has a $\mathrm{pH}$ of 1.6 , which is lower than universal adhesives evaluated in this study, and it also contains 10-MDP. However, IBU did not show a higher bond strength and in-situ DC when active-SE was compared to ER. IBU is a HEMA-free adhesive and although promising results in terms of bond strength have been reported for HEMA-free adhesives, ${ }^{39}$ they are more prone to phase separation at the interface, as previously shown by Loguercio et al. ${ }^{22}$ In addition, IBU contains acetone as a solvent. Therefore, the active-SE application could accelerate the solvent evaporation and impair the efficiency of adhesive penetration inside the enamel-resin interface. ${ }^{40}$

Although, the SBU showed a higher $\mathrm{pH}$ of $2.7^{22,28}$ compared to the other universal adhesives tested, higher values in terms of muSBS and in-situ DC were observed when SBU was applied, especially when compared to CUB and IBU. SBU is the only universal 
adhesive evaluated, that contains two functional monomers: $\mathrm{MDP}^{36-38}$ and methacrylate-modified polyalkenoic acid copopolymer ${ }^{41}$ which potentiate the chemical interaction of the SBU with sound and fluorotic enamel..$^{22,28}$

Despite that, changing the mode of application from passive to active resulted in mean $\mu$ SBS similar to that of the ER application mode for both substrates, statistically significant higher mean $\mu$ SBSs were obtained in sound enamel than in fluorotic enamel. It has been shown that there are inherent structural differences between sound and fluorotic enamel. Even though fluorotic enamel show an outer hypermineralized layer owing to greater fluoride incorporation, interprismatic areas, which are potentially less mineralized due to greater retention of matrix proteins in fluorotic enamel, can increase porosity in the hypomineralized subsurface $^{42,43}$ Thus, it is worth mentioning that, although fluorotic enamel has a higher fluoride content, it was enough to compensate the greater structural weakness of the hypomineralized and porosity subsurface, adversely affecting the adequate performance of the adhesive system., ${ }^{9,12}$

However, even that for the microshear bond strength test is necessary to be flattened enamel surface, the EDX in this study supports the findings of structural differences between sound and fluorotic enamel. The amount of fluoride was higher in fluorotic enamel when compared to sound enamel, but fluorotic enamel also showed a significant reduction of the $\mathrm{Ca}$ and P peak intensity (Figure 2). Additionally, the SEM images showed more topography alteration in fluorotic enamel than in sound enamel (Figure 1), similar to other studies.,12,16 Thus, alterations of the prism core, dissolution of the prism wall, porous-rich areas more evident only in fluorotic enamel (Figure 1).
One should not deny that active application may be recommended for universal adhesives applied in sound and fluorotic enamel, once there is a clear advantage of active application over selective enamel etching. Thus, active application of universal adhesives in the self-etch mode may be a clinical alternative to increase bonding to fluorotic enamel, without etching enamel with phosphoric acid. This omits the critical etch-and-rinse phase, which makes the clinical procedure not only shorter but also easier. ${ }^{11}$

However, bonding to a resin-fluorotic enamel interface did not show the same results as bonding to a resin-sound enamel interface. Therefore, further studies should be conducted to evaluate the association of active application with an increase in application time or increase in solvent evaporation time.

\section{Conclusion}

Bonding to sound enamel showed better results compared to fluorotic enamel, independent of the application mode. The active application of universal adhesives in the SE mode showed resin-enamel bond strength and in-situ DC values similar to etch-andrinse procedures for both substrates. Thus, it could be considered an alternative simplification to bonding enamel with universal adhesive.

\section{Acknowledgments:}

This study was supported by the National Council for Scientific and Technological Development from the Brazilian Government [303332/2017-4 and 305588/2014-1] and the Coordination of Improvement of Higher-Level Personnel (CAPES) from the Brazilian Ministry of Education.

\section{References}

1. Pretty IA. High fluoride concentration toothpastes for children and adolescents. Caries Res. 2016;50 Suppl 1:9-14. https://doi.org/10.1159/000442797

2. Buzalaf MA, Levy SM. Fluoride intake of children: considerations for dental caries and dental fluorosis. Monogr Oral Sci. 2011;22:1-19. https://doi.org/10.1159/000325101

3. Horowitz HS, Driscoll WS, Meyers RJ, Heifetz SB, Kingman A. A new method for assessing the prevalence of dental fluorosis: the Tooth Surface Index of Fluorosis. J Am Dent Assoc. 1984 Jul;109(1):37-41. https://doi.org/10.14219/jada.archive.1984.0268 
4. Perdigão J, Lam VQ, Burseth BG, Real C. Masking of enamel fluorosis discolorations and tooth misalignment with a combination of at-home whitening, resin infiltration, and direct composite restorations. Oper Dent. 2017 Jul/Aug;42(4):347-56. https://doi.org/10.2341/16-181-T

5. Muñoz MA, Arana-Gordillo LA, Gomes GM, Gomes OM, Bombarda NH, Reis A, et al. Alternative esthetic management of fluorosis and hypoplasia stains: blending effect obtained with resin infiltration techniques. J Esthet Restor Dent. 2013 Feb;25(1):32-9. https://doi.org/10.1111/j.1708-8240.2012.00527.x

6. Akpata ES. Occurrence and management of dental fluorosis. Int Dent J. 2001 Oct;51(5):325-33. https://doi.org/10.1002/j.1875-595X.2001.tb00845.x

7. Van Meerbeek B, De Munck J, Yoshida Y, Inoue S, Vargas M, Vijay P, et al. Buonocore memorial lecture. Adhesion to enamel and dentin: current status and future challenges. Oper Dent. 2003 May-Jun;28(3):215-35.

8. Fejerskov O, Manji F, Baelum V. The nature and mechanisms of dental fluorosis in man. J Dent Res. 1990 Feb;69(Spec No):692-700. https://doi.org/10.1177/00220345900690S135

9. Torres-Gallegos I, A Martinez-Castañon G, Loyola-Rodriguez JP, Patiño-Marin N, Encinas A, Ruiz F, et al. Effectiveness of bonding resin-based composite to healthy and fluorotic enamel using total-etch and two self-etch adhesive systems. Dent Mater J.

2012;31(6):1021-7. https://doi.org/10.4012/dmi.2012-140

10. Fejerskov O, Larsen MJ, Richards A, Baelum V. Dental tissue effects of fluoride. Adv Dent Res. 1994 Jun;8(1):15-31. https://doi.org/10.1177/08959374940080010601

11. Van Landuyt KL, Mine A, De Munck J, Jaecques S, Peumans M, Lambrechts P, et al. Are one-step adhesives easier to use and better performing? Multifactorial assessment of contemporary one-step self-etching adhesives. J Adhes Dent. 2009 Jun;11(3):175-90.

12. Weerasinghe DS, Nikaido T, Wettasinghe KA, Abayakoon JB, Tagami J. Micro-shear bond strength and morphological analysis of a self-etching primer adhesive system to fluorosed enamel. J Dent. 2005 May;33(5):419-26. https://doi.org/10.1016/i.jdent.2004.11.004

13. Shida K, Kitasako Y, Burrow MF, Tagami J. Micro-shear bond strengths and etching efficacy of a two-step self-etching adhesive system to fluorosed and non-fluorosed enamel. Eur J Oral Sci. 2009 Apr;117(2):182-6. https://doi.org/10.1111/j.1600-0722.2009.00609.x

14. Ermis RB, De Munck J, Cardoso MV, Coutinho E, Van Landuyt KL, Poitevin A, et al. Bonding to ground versus unground enamel in fluorosed teeth. Dent Mater. 2007 Oct;23(10):1250-5. https://doi.org/10.1016/i.dental.2006.11.005

15. Ratnaweera PM, Nikaido T, Weerasinghe D, Wettasinghe KA, Miura H, Tagami J. Micro-shear bond strength of two all-in-one adhesive systems to unground fluorosed enamel. Dent Mater J. 2007 May;26(3):355-60. https://doi.org/10.4012/dmi.26.355

16. Ertuğrul F, Türkün M, Türkün LS, Toman M, Cal E. Bond strength of different dentin bonding systems to fluorotic enamel. J Adhes Dent. 2009 Aug; $11(4): 299-303$.

17. Ateyah N, Akpata E. Factors affecting shear bond strength of composite resin to fluorosed human enamel. Oper Dent. 2000 May-Jun;25(3):216-22.

18. Ng'ang'a PM, Ogaard B, Cruz R, Chindia ML, Aasrum E. Tensile strength of orthodontic brackets bonded directly to fluorotic and nonfluorotic teeth: an in vitro comparative study. Am J Orthod Dentofacial Orthop. 1992 Sep;102(3):244-50. https://doi.org/10.1016/S0889-5406(05)81059-5

19. Hanabusa M, Mine A, Kuboki T, Momoi Y, Van Ende A, Van Meerbeek B, et al. Bonding effectiveness of a new 'multi-mode' adhesive to enamel and dentine. J Dent. 2012 Jun;40(6):475-84. https://doi.org/10.1016/i.jdent.2012.02.012

20. Perdigão J, Sezinando A, Monteiro PC. Effect of substrate age and adhesive composition on dentin bonding. Oper Dent. 2013 May-Jun;38(3):267-74. https://doi.org/10.2341/12-307-L

21. Muñoz MA, Luque I, Hass V, Reis A, Loguercio AD, Bombarda NH. Immediate bonding properties of universal adhesives to dentine. J Dent. 2013 May;41(5):404-11. https://doi.org/10.1016/i.jdent.2013.03.001

22. Loguercio AD, Muñoz MA, Luque-Martinez I, Hass V, Reis A, Perdigão J. Does active application of universal adhesives to enamel in self-etch mode improve their performance? J Dent. 2015 Sep;43(9):1060-70. https://doi.org/10.1016/i.jdent.2015.04.005

23. Miyazaki M, Hinoura K, Honjo G, Onose H. Effect of self-etching primer application method on enamel bond strength. Am J Dent. 2002 Dec;15(6):412-6

24. Torres CR, Barcellos DC, Pucci CR, Lima GM, Rodrigues CM, Siviero M. Influence of methods of application of self-etching adhesive systems on adhesive bond strength to enamel. J Adhes Dent. 2009 Aug;11(4):279-86.

25. Rozier RG. Epidemiologic indices for measuring the clinical manifestations of dental fluorosis: overview and critique. Adv Dent Res. 1994 Jun;8(1):39-55. https://doi.org/10.1177/08959374940080010901

26. Shimaoka AM, de Andrade AP, Cardoso MV, de Carvalho RC. The importance of adhesive area delimitation in a microshear bond strength experimental design. J Adhes Dent. 2011 Aug;13(4):307-14. https://doi.org/10.3290/i.jad.a19819

27. Muñoz MA, Baggio R, Emilio Mendes YB, Gomes GM, Luque-Martinez I, Loguercio AD, et al. The effect of the loading method and cross-head speed on resin-dentin microshear bond strength. Int J Adhes Adhes. 2014;50:136-41. https://doi.org/10.1016/j.ijadhadh.2014.01.024 
28. Cardenas AM, Siqueira F, Rocha J, Szesz AL, Anwar M, El-Askary F, et al. Influence of conditioning time of universal adhesives on adhesive properties and enamel-etching pattern. Oper Dent. 2016 Sep-Oct;41(5):481-90. https://doi.org/10.2341/15-213-L

29. Perdigão J, Lopes MM, Gomes G. In vitro bonding performance of self-etch adhesives: II—ultramorphological evaluation. Oper Dent. 2008 Sep-Oct;33(5):534-49. https://doi.org/10.2341/07-13330

30. Perdigao J, Muñoz M, Luque-Martinez I, Reis A, Loguercio A. Enamel etching patterns of universal adhesives - FESEM analyses. J Dent Res. 2014;93(Special issue A):abstract 474.

31. Loguercio AD, Loeblein F, Cherobin T, Ogliari F, Piva E, Reis A. Effect of solvent removal on adhesive properties of simplified etch-and-rinse systems and on bond strengths to dry and wet dentin. J Adhes Dent. 2009 Jun;11(3):213-9.

32. Chen L, Suh BI. Effect of hydrophilicity on the compatibility between a dual-curing resin cement and one-bottle simplified adhesives. J Adhes Dent. 2013 Aug;15(4):325-31. https://doi.org/10.3290/i.jad.a28604

33. Van Landuyt KL, Snauwaert J, De Munck J, Peumans M, Yoshida Y, Poitevin A, et al. Systematic review of the chemical composition of contemporary dental adhesives. Biomaterials. 2007 Sep;28(26):3757-85. https://doi.org/10.1016/i.biomaterials.2007.04.044

34. Cadenaro M, Breschi L, Rueggeberg FA, Suchko M, Grodin E, Agee K, et al. Effects of residual ethanol on the rate and degree of conversion of five experimental resins. Dent Mater. 2009 May;25(5):621-8. https://doi.org/10.1016/i.dental.2008.11.005

35. Pashley DH, Tay FR. Aggressiveness of contemporary self-etching adhesives. Part II: etching effects on unground enamel. Dent Mater. 2001 Sep;17(5):430-44. https://doi.org/10.1016/S0109-5641(00)00104-4

36. Yoshida Y, Nagakane K, Fukuda R, Nakayama Y, Okazaki M, Shintani H, et al. Comparative study on adhesive performance of functional monomers. J Dent Res. 2004 Jun;83(6):454-8. https://doi.org/10.1177/154405910408300604

37. Yoshihara K, Yoshida Y, Hayakawa S, Nagaoka N, Torii Y, Osaka A, et al. Self-etch monomer-calcium salt deposition on dentin. J Dent Res. 2011 May;90(5):602-6. https://doi.org/10.1177/0022034510397197

38. Fukegawa D, Hayakawa S, Yoshida Y, Suzuki K, Osaka A, Van Meerbeek B. Chemical interaction of phosphoric acid ester with hydroxyapatite. J Dent Res. 2006 Oct;85(10):941-4. https://doi.org/10.1177/154405910608501014

39. Van Landuyt KL, Snauwaert J, Peumans M, De Munck J, Lambrechts P, Van Meerbeek B. The role of HEMA in one-step self-etch adhesives. Dent Mater. 2008 Oct;24(10):1412-9. https://doi.org/10.1016/i.dental.2008.02.018

40. Van Landuyt KL, De Munck J, Snauwaert J, Coutinho E, Poitevin A, Yoshida Y, et al. Monomer-solvent phase separation in one-step self-etch adhesives. J Dent Res. 2005 Feb;84(2):183-8. https://doi.org/10.1177/154405910508400214

41. Perdigão J, Sezinando A, Monteiro PC. Laboratory bonding ability of a multi-purpose dentin adhesive. Am J Dent. 2012 Jun;25(3):153-8.

42. Martinez-Mier EA, Lippert $F$. Teeth with mild and moderate enamel fluorosis demonstrate increased caries susceptibility in vitro. J Evid Based Dent Pract. 2017 Sep;17(3):293-5. https://doi.org/10.1016/i.jebdp.2017.07.001

43. Martinez-Mier EA, Shone DB, Buckley CM, Ando M, Lippert F, Soto-Rojas AE. Relationship between enamel fluorosis severity and fluoride content. J Dent. 2016 Mar;46:42-6. https://doi.org/10.1016/i.ident.2016.01.007 